\title{
Compassion Practices
}

\author{
Paul Condon ${ }^{1}$, John Makransky² \\ Prepared for Integrative Medicine, $5^{\text {th }}$ Ed., \\ Edited by David Rakel \& Vincent Minichiello
}

${ }^{1}$ Department of Psychology

Southern Oregon University

1250 Siskiyou Blvd

Ashland, OR 97520

condonp@sou.edu

${ }^{2}$ Department of Theology

Boston College

140 Commonwealth Ave

Chestnut Hill, MA 02467

john.makransky@bc.edu 
Abstract: Healthcare providers seek to access a power of sustainable, inclusive, and unconditional care and compassion for self and others beyond empathic distress, secondary trauma, and burnout. To support that goal, in this chapter, we present three compassion meditations that serve two purposes: 1) to empower the ability to be with your own difficult emotions and feelings in a healing way, and 2) to extend empathy and compassion to others with increasing sustainability and inclusivity. Providers can practice these meditations themselves and carry forward that practice into clinical work, both in their embodied presence to their patients and, if appropriate and beneficial, by explicitly sharing these practices with interested patients.

Key words: empathy, care, burnout, fatigue, meditation, stress 
Healthcare providers who serve patients that are suffering face a dilemma: whether to empathize with those patients to empower their care for them, or to avoid empathizing with patients to protect themselves from secondary trauma, fatigue, and burnout. ${ }^{1}$ On one hand, empathy and compassion can inform the provider's discernment of a patient's overall health, build trust, improve diagnoses, and promote physical and emotional benefits for patients. Such benefits include reduced pain, better medical adherence, faster physical recovery, and better mental health. ${ }^{2,3}$ On the other hand, empathy as ordinarily experienced can be stressful for providers, since emotionally connecting with patients in their suffering can lead to recurrent feelings of empathic distress. This puts providers at risk for physical and emotional difficulties, such as secondary trauma and emotional depletion, which reduce their effectiveness as caregivers and can contribute to compassion fatigue and burnout.

Because of those potential difficulties with empathy, understandably, many providers choose the second horn of the dilemma — to avoid empathizing with patients ${ }^{4}$-and as a result, they fail to make an empathetic and compassionate connection with their patients. This can also have detrimental consequences for their patients' recovery and healing process. ${ }^{3,5}$ And the consequent sense of ineffectiveness for providers may then negatively impact their career satisfaction and purpose, violate their moral imperative to benefit their patients, and even interfere with their relationships outside of work. ${ }^{6,7}$ Either choice then, having empathy for suffering patients or avoiding empathy, seems like it could reduce providers' effectiveness and put them at risk for compassion fatigue and burnout.

The medical field has recognized an alarming deficiency of compassionate rapport between provider and patient, calling it a "crisis of compassion". ${ }^{5}$ Several factors explain this crisis of compassion within the healthcare system. One is the tendency by many providers to 
avoid empathy for the reasons noted above. Another important factor are systemic barriers to compassionate connection between providers and patients. These include a lack of formal training centered on compassion, an onerous workload that requires too much time spent on electronic records and insurance requirements, ${ }^{8}$ a lack of conceptual clarity around empathy and compassion, and a narrow focus on biomedical data that may exclude a complementary emphasis on human connection. ${ }^{5,9}$ Indeed, historically, systems of medical training have promoted a style of "clinical empathy" that emphasizes professional distance and detached reasoning rather than affective resonance with patients. , $^{3,10}$

Consequently, many medical providers choose to avoid empathy and to suppress emotions that would inform their empathy, both to maintain professional distance and to preserve their own well-being and ability to survive their work. But when healthcare providers routinely avoid empathizing and deny their own emotions, their emotions may take unconscious expression in harmful ways, such as a tendency to dehumanize, blame, or even derogate patients. ${ }^{11,12}$ Though strategies to suppress affective feelings and to avoid empathy might offer the provider some relief in the moment, over time they can make one's care less effective. The consequences can include poorer clinical judgment, lack of energy, increased medical errors, higher patient dissatisfaction, and emotional breakdown for providers. ${ }^{9,13-17}$ One study estimates that over $50 \%$ of physicians experience burnout, partly stemming from the problems created by avoiding feelings that inform affective empathy and compassion. ${ }^{18}$ In the end, patients and providers both suffer when providers lack or avoid empathy and compassion.

To address this crisis of compassion, healthcare providers and systems of medical education are turning to programs for training in empathy and compassion. ${ }^{19}$ Initial evidence suggests that compassion-based meditation programs can benefit healthcare providers' mental 
health. ${ }^{20}$ Such programs aim to help providers access a power of sustainable, inclusive, and unconditional care and compassion beyond what they had previously experienced—beyond recurrent empathic distress, secondary trauma, burnout, and bias. Healthcare providers need a source of replenishment and support that they can repeatedly return to. They need this both to foster their own ability to process their feelings in a healthy way and in order to extend empathy, care, and compassion to others more sustainably and inclusively.

In our view, such sustainable empathy and compassion emerges from a communal, relational field of caring support. When someone experiences how it feels to be seen as worthy of care and supported in care, she can establish the inner core of security that she needs to process her difficult feelings in a restorative and healing way. To be seen and supported like that also empowers her to see, empathize with, and support others in the same way. We refer to this as the relational starting point for compassion training. ${ }^{21}$ Meditations on compassion from contemplative cultures follow that very pattern, and can be adapted for secular application in caring professions. ${ }^{22}$

This pattern of care, then, begins by experiencing oneself as embraced in a field of caring support, which increases one's capacity to extend care to others. That pattern is shared not only across the world's spiritual cultures but is also prominent within attachment theory, one of the most influential perspectives in developmental and social psychology. Through the lens of attachment theory, we assert that communal and ritual practices prominent in spiritual traditions throughout the world function to help practitioners develop an unlimited secure base that they can return to again and again for replenishment, healing, and empowerment. ${ }^{21,22}$ Through such patterns of practice, these contemplative practitioners experience themselves and their world as held within the unwavering support of their spiritual ancestors and benefactors, which empowers 
them, like their spiritual benefactors, to extend care to others in increasingly inclusive, unconditional ways.

Research on attachment priming suggests that this same pattern of practice can be accomplished in modern contexts by recalling and then re-experiencing a simple moment of caring connection with any being, so as to draw out one's own capacities for care. ${ }^{21}$ We posit that repeatedly reinhabiting such moments in meditative practice can empower health providers to enter into empathic resonance with patients while avoiding the risks of burnout and secondary trauma that come with empathic distress. Indeed, research has shown that attachment priming increases emotion regulation abilities, the patience to listen to others' emotions, reduces bias toward outgroups, and increases compassionate action to alleviate others suffering. ${ }^{23-25}$

In this chapter, we present three different compassion meditations that are designed to establish an inner core of security (see Figure 1). This core of security serves two purposes: 1) to empower deep self-care; here, the ability to be with your own difficult emotions and feelings in a healing way, and 2) to be able to extend empathy and compassion to others with increasing sustainability and inclusivity. These meditations have been adapted from Tibetan Buddhism into a form that can be applied in modern secular contexts, within a modern secular program called "sustainable compassion training" (SCT). ${ }^{21,22}$ These meditations progressively aim to establish an outer and inner secure base of caring qualities. A practitioner can then draw on the wellspring of those qualities to enter safely into empathic resonance with others who are suffering, to inform and energize caring, compassionate action.

Our aim here is to establish the possibility for healthcare providers to practice these meditations and carry forward that practice into clinical encounters both in their embodied presence and, if appropriate and beneficial, by sharing these practices with interested patients. 
Providers who wish to share these practices with patients should first develop experiential knowledge through their own personal practice, so that the practices can be shared with others from that grounded experience.

Meditation 1: Field of Care.* The first, foundational practice of sustainable compassion training (SCT) involves establishing a field of care, from which a practitioner learns to experience herself as seen and held in care, which helps evoke and strengthen her own caring capacities. A field of care for meditative visualization can be constructed in several ways: by identifying and reinhabiting a moment of caring connection with another being that makes you happy to recall, by bringing to mind an inspiring benefactor or a deeply meaningful spiritual figure(s). ${ }^{\dagger}$ To do this, practitioners are provided with examples of diverse examples of caring moments and benefactors, and invited to fill in the content of the meditation in the way that feels most connecting and uplifting for that person. This can be done with a caring moment from any time in the practitioner's life when another person was seeing her in her deep worth, was happy to be with her, offered support, listened to her, or wished her well. Or the practice can be engaged by imagining the presence of a benefactor to whom the practitioner feels grateful, or spiritual figure(s) from that practitioner's own tradition who are inspiring to her. The practice can also be engaged by calling to mind a moment with a pet or a moment in a special place, perhaps in nature, where the practitioner felt deeply well, safe, and at home. Finally, the practice can be carried out by calling to mind a moment of care between others that the practitioner

\footnotetext{
${ }^{*}$ The meditations presented here are partly reproduced from material that appeared in Condon, P., \& Makransky, J. (2020). Sustainable Compassion Training: Integrating meditation theory with psychological science. Frontiers in Psychology, 11: 2249.

${ }^{\dagger}$ The field of care practice is adapted from Tibetan Buddhist practices of refuge and guru yoga (Thondup, 1996, pp. 165-173; D. K. Rinpoche, 1996, pp. 29-36, 73-86; S. Rinpoche, 2009, 146-149). The adaptations presented here make this pattern of practice accessible for a wider public to find a simple, direct entry into the heart of this pattern of practice, and for Buddhists or other spiritual practitioners to help enhance their practice.
} 
witnessed and that brought joy to her, similar to the concept of moral elevation. ${ }^{26:}$ The important element is that the field of care evoked by the practitioner genuinely brings joy to or feels uplifting to her, which signifies that it is already providing access to innate caring qualities. After settling more and more fully into the felt sense of those loving qualities - such as deep acceptance, warmth, being seen as worthy, love, inner safety, joy, etc. - - the practitioner is instructed to release the visualization of the field of care, and to relax her mind directly into that felt sense of love, warmth and acceptance. This can help the mind to relax deeply, release its images and mental frameworks, and fall gently, spaciously open. We refer to this final portion of the meditation as the "releasing phase," which supports deepening trust and unification with the spacious source of the caring qualities in the depth of one's mind, from which further such qualities can emerge. A guided meditation can be accessed here: https://foundationforactivecompassion.org/media/listen/field-of-care-meditation/.

An important feature of this practice is its consistency with current perspectives on grounded and situated cognition. ${ }^{27,28}$ According to theories of grounded cognition, when we recall a memory from our life, it is re-enacted in multiple systems of the brain: motor, visual, kinesthetic, affective, and so forth. During the field of care practice, when practitioners reinhabit a caring moment from the past as happening now, visualizing and simulating its felt sense of security, they are experiencing that moment as a fully embodied experience, with all the qualities of care, love, warmth, acceptance, peace, and well-being that come with it.

Following this meditation, it is helpful to name the caring qualities that were experienced during the meditation. By naming felt qualities, such as love, warmth, acceptance, ease,

\footnotetext{
${ }^{\ddagger}$ An additional way to construct a field of care in SCT is to call to mind a moment when the practitioner herself offered care to another. This may be the best starting point for some people who initially have difficulty receiving care. Nevertheless, we hypothesize that moments of receiving care will eventually also need to be engaged for this practice to reach its maximal effect. ${ }^{21}$
} 
tenderness, safety, feeling seen, gratitude, inner freedom, openness, peace, feeling at home, joy, restfulness, etc., practitioners begin to cultivate an increasing awareness of, and receptivity to, a full spectrum of their innate capacities of care. The capacity to name a full spectrum of caring qualities is analogous to the concept of emotion granularity in affective science, in which labeling emotions with increasing precision and specificity leads to a richer emotional life characterized by greater well-being, discernment, and flexibility around emotional responding. ${ }^{29-}$ ${ }^{32}$ We hypothesize that increasing granularity for caring qualities should lead to an increasing ease with which to notice, access and draw upon such qualities.

Meditation 2: Compassionate Presence to Feelings. The second SCT meditation, called "compassionate presence to feelings" is designed to offer a new way to become present to difficult feelings that arise both in meditation and in daily life. This practice can serve as an extension of the field of care meditation by helping practitioners draw further on their innate caring capacities. In this meditation, the practitioner gently welcomes all feelings into a space of unconditional acceptance and care, where they can relax and heal. By becoming so compassionately present to our own feelings, we can more easily be present to others and their feelings in the same way.

Intense, stressful aspects of healthcare work, including repeated exposure to others' suffering and a demanding workload, trigger many difficult feelings. As noted in the introduction to this chapter, providers understandably seek to avoid difficult feelings by trying to suppress, ignore or distract themselves from them. But when people seek to avoid or suppress feelings, over time, those feelings ironically increase, ${ }^{33,34}$ yielding greater sympathetic nervous system reactivity, ${ }^{35}$ which manifests as physical and emotional tightness, including heightened blood pressure, vasoconstriction, and avoidance motivation. ${ }^{36,37}$ In turn, such suppression also disrupts 
interpersonal communication and relationship quality. ${ }^{6,7}$ With repetition of emotional suppression over time, these physiological and psychological effects can lead to negative health consequences for mind and body, including loneliness, hypertension, and coronary artery disease. ${ }^{38,39}$ Such stress and tightness also make it difficult to be fully present to patients in a caring way. These tendencies are exacerbated by many of the systems that shape our emotional lives, including our families, communities, educational institutions, and professional environments. Each such kind of community often conveys and reinforces regulation strategies to suppress, avoid, deny, or distract ourselves from emotional feelings. ${ }^{40-43}$

All such difficulties with emotional suppression and avoidance suggest a need to learn how to process feelings and emotions in a deeply healing way. The next meditation, compassionate presence to feelings, ${ }^{\S}$ helps feelings that arise in our lives and work to process themselves in a restorative way. This offers a life-giving alternative to the systemic tendency to suppress or distract ourselves from difficult feelings, while further evoking our underlying capacities of care and compassion.

In this meditation, the practitioner learns how to welcome his feelings into a compassionate space where they can relax, settle in their own time, and as needed, heal in their own natural way. "Feelings" here refers to the pleasant, unpleasant, and neutral feeling tones that accompany our physical and mental experiences and to all the emotions with which they are associated. This kind of meditation shows practitioners that they do not have to avoid or suppress their feelings and reactions or habitually act them out. Instead, the practitioner becomes safely aware of feelings in a gentle, deeply allowing way that gives them all the space they need to relax, settle, and find their own place — ultimately a place of inner healing and releasing. Because

\footnotetext{
$\S$ This practice has been adapted from the "Handshake practice" taught by Tsoknyi Rinpoche (T. Rinpoche, 2012, pp 146-153).
} 
of their constructed nature, emotional feelings can release and heal in that way if they have the space and freedom to do so. This view builds on constructivist theories of the mind in modern psychology and neuroscience.

The Theory of Constructed Emotion ${ }^{44}$ points to the underlying emptiness of all emotions: emotions are constructed from domain-general capacities (e.g., attention, perception, conceptualization, interoception) in relation to social conditioning without any underlying essence. Although emotions have a relative, social reality, they do not have an ultimate, substantial reality. ${ }^{45}$ SCT adds to the Theory of Constructed Emotion by establishing a "holding environment" ${ }^{\prime 6,47}$ in which emotions can self-release. By creating a space in which emotions are not elaborated on, ruminated about, or responded to, the process of constructing an emotion can relax and unwind within the space of compassionate awareness, revealing the underlying emptiness and healing property available right within the emotion. This contemplative orientation to emotions aligns with research on mindfulness and emotional reactivity, which shows that acceptance is a key ingredient of mindfulness meditation ${ }^{48,49}$ and allied therapies that relieve stress. ${ }^{50,51}$

In this practice, the practitioner learns to be more at home with his emotional feelings, even difficult emotions, and they feel safer with him, since they are not being rejected, denied or avoided. This transforms his way of being with others, since his ability to be present to his own feelings safely, with openness and compassion, is what enables her to be present to other people and their feelings in the same way. It is important to highlight that this practice differs from selfcompassion: the intention is not to bring extraneous kindness to emotions, but rather, to simply allow them to be, with a space of deep acceptance that lets them free themselves by revealing their emptiness from within. Nothing extra is applied to the emotion. 
This meditation has four aspects: 1) notice the feeling within whatever state of mind or body is occurring; 2) allow the feeling to have all the space it needs to find its own place; 3) rest with or within the feeling; 4) then just let everything be, with spaciousness. In the meditation, the practitioner is instructed to become aware first of a physical sensation, then of an emotional feeling by sensing how it feels within one's body—not just thinking about it in an analytical, disembodied way. The practitioner is guided to become aware of any such physical or emotional feeling in a fully allowing way, gently welcoming it in a spacious, accepting manner that lets it settle in its own time. Then, if another physical or emotional feeling replaces the first feeling, the practitioner becomes aware of that sensation in the same deeply allowing, spacious way. A guided meditation can be accessed here:

https://foundationforactivecompassion.org/media/listen/compassionate-presence-to-feelings/.

Several key lessons emerge from this compassionate presence to feelings meditation. First, there can be a healing power to the meditation. For a practitioner to be with all of her physical and emotional feelings in such an unconditional way helps her mind and body to relax deeply, unclench, and begin to heal from within. Second, this practice provides the compassionate holding environment that emotions need to reveal their empty nature and further positive qualities of awareness that emerge from that. In compassionate presence practice, emotional feelings are provided a safe space to open into underlying feelings and eventually into the empty core of the feelings, where a deep sense of relief, warmth, inner safety and well-being can be experienced. Third, this practice can empower inner steadiness and courage. The process of letting feelings open and heal from within generates equanimity toward feelings and the situations that evoke them. There is a growing awareness that the practitioner does not need to be afraid of the feelings that others trigger in her, which gives her the courage to work with 
challenging people and circumstances. Fourth, this practice can facilitate compassionate presence to others: the power to be with her own feelings with such compassion and steadiness becomes a power to be with others and their feelings in the same way. Fifth, in the ways noted above, compassionate presence meditation further establishes the core of security that is needed to extend care and compassion to others in a more reliable, inclusive and unconditional way. This is possible as the practitioner becomes more unconditional and steadfast with regard to her own feelings.

Meditation 3: Taking empathy into compassion instead of empathic distress. We define compassion as a caring concern for beings that empathizes with them in their suffering and wants to take action to alleviate it. To cultivate effective, empathetically-informed care, while avoiding empathic distress, we propose that people can make a conscious choice to feel empathy for others in a way that informs and energizes compassion rather than in a way that devolves into empathic distress. This view aligns with motivated choice theories of empathy, which assert that empathy is not a limited resource, but a resource that people can consciously increase by choosing to feel empathy and expand the scope of their care. ${ }^{52-55} \mathrm{We}$ adopt and expand this perspective with the additional resource of the relational starting point, which provides the outer and inner secure base needed to direct one's empathy for others who are suffering into compassion rather than empathic distress.

The addition of the relational starting point to support empathic choice aligns with social baseline theory (SBT), ${ }^{56,57}$ which suggests that people serve as a bioenergetic resource that supports emotion regulation for each other. The mere presence of supportive others can reduce the brain's reactivity to threat. ${ }^{58}$ The energetic resources made available by sympathetic others are not limited to their physical presence; reduced threat reactivity can also occur by imagining 
supportive others as illustrated by research on attachment priming. ${ }^{23,25}$ A relational starting point of meditation provides the energetic resource and secure base needed to transform the pain of empathy for suffering others into empathic concern for them rather than self-involved empathic distress.

An additional concept from health and social psychology, called "reappraisal," also informs our third meditation on compassion. The biopsychosocial (BPS) theory of stress suggests that threat and challenge constitute two different physiological responses to stress. ${ }^{59}$ Challenge is characterized by heightened sympathetic activity, a more efficient cardiovascular profile (e.g,, vasodilation in arteries), and stronger approach motivations. Threat is characterized by heightened sympathetic activity, HPA, a less efficient cardiovascular profile (e.g., vasoconstriction in arteries), and avoidance motivations (i.e., avoiding challenges, giving up, preparing for defeat). When stress is reappraised as helpful, rather than harmful, people experience a physiological challenge response rather than a threat response, which improves performance and well-being. ${ }^{60,61}$ Reappraisal is an effective strategy for making use of the physiological energy of stress.

The compassion meditation below extends the application of reappraisal to the pain of empathy that one often feels when empathizing with others who are suffering. In this meditation, the practitioner transforms the pain of his own empathy for others who are suffering into an energy of compassion for them. This is a form of reappraisal, akin to reappraising stress as a helpful energy for responding to challenges in the environment. ${ }^{62}$ Within the meditation, the practitioner is guided to reappraise the pain of empathy as a resource that energizes compassion, rather than as a form of distress. This meditation can help the practitioner become more fully present and responsive to others' suffering without being overwhelmed by empathic distress or 
thinking that he has to turn away. Instead, the practitioner can experience his deepening awareness of others' suffering as a fuel of empathy and compassion that makes him more fully present to them while generating a strong motivation for caring action. Two key purposes, then, of the next meditation practice are: 1) to develop skill at channeling empathy into compassion instead of empathic distress., and 2) to bring out a strong will of compassion for action.

The practitioner begins with the meditation by reinhabiting his field of care. While continuing to resonate with a felt sense of care as a secure base, he then brings to mind a person or group whose suffering deeply touches his heart, while sensing the suffering that they must be experiencing. The practitioner is guided in generating increasing empathy for the others' suffering by asking: How must it feel for them in heart, mind, and body? What other feelings may be arising for them? The practitioner is encouraged to take time to deepen his affective and cognitive empathy in this way. At the same time, the practitioner is explicitly told to avoid getting stuck in the pain of this empathy. Rather, he makes a conscious choice to let the power of this empathy become an intense energy and attitude of compassion that wishes the others free of the pain and suffering that impedes their wellbeing and happiness. The practitioner lets this wish and energy of compassion radiate powerfully from his heart to that person or group, infusing their whole being and environment in its radiant power, wishing them deeply well and free of the causes of their distress and suffering, each in their own best way. After some time, the compassionate wish and energy is extended more expansively to all beings who experience the various sufferings of living and dying, infusing them and their environment in the same radiant power of compassion, wishing them well and free. The meditation concludes with the releasing phase, in which the compassion evoked by the meditation helps the practitioner relax deeply into spaciousness, clarity and warmth, where all patterns of thought and feeling are permitted to 
unwind and release. A guided meditation can be accessed here:

\section{https://foundationforactivecompassion.org/media/listen/bringing-out-a-strong-will-of-}

\section{compassion-for-action/.}

Several key learnings emerge from this meditation. First, as noted, empathic distress occurs when a person's attention turns inward on himself, so he gets caught up in his own feelings of pain from empathizing with others in their suffering. In contrast, the power of care and compassion in this meditation directs one's empathic attention compassionately outward toward others, so the practitioner does not internalize the suffering as empathic distress. Second, a further protection from empathic distress includes the insight cultivated in the prior meditations - the awareness that suffering is never the only reality here, but is embraced in a larger reality of spacious warmth and care in which it can transform and deeply heal or release. Finally, the instruction of this meditation also points to a direction of creative responsiveness for action, by turning one's attention to causes of distress and suffering, encouraging the practitioner to deepen his learning and response to such causes.

\section{Conclusion}

The meditations in this chapter aim to establish an inner core of security that offers a healing way to process difficult emotions and feelings, while also empowering the possibility to extend empathy and compassion to others with increasing sustainability. These practices can support healthcare providers and patients, as providers learn repeatedly to engage the practices. By familiarizing with these meditations in repeated practice, the qualities of care, compassion, and equanimity that they evoke can become integrated into providers' interactions with patients, as part of their embodied presence. Then as appropriate or needed, providers can explicitly share these practices with interested patients. 
In closing, we echo a cautionary note voiced by physicians and healthcare workers: burnout is a systemic issue that must be addressed at an organizational level. ${ }^{5,9}$ Meditation practices should not be offered as a tactic to place further responsibility on individual providers. Failures to establish a compassionate, trusting relationship with patients can be attributed, in part, to increasing demands to attend to administrative and financial interests, which takes time and attention away from one's patients. This can give rise to moral injury when the provider comes to believe that she is not serving the best interest of patients. ${ }^{8}$ Our hope is that the compassion practices offered here can not only empower providers to avoid individual empathic distress and depletion, but also empower them to work for systemic change. Organizations that foster communal connection and shared meditation practice can establish relationships between administrators, providers, and patients. Research inspired by attachment and social baseline theories suggests that humans function optimally when embedded within such a network of supportive social connections and relationships. These forms of connectivity enhance emotion regulation capacities and help establish the core of security needed to offer care inclusively and effectively to others. A culture of care and compassion can help empower more authentic compassion and care for everyone. 


\section{Note Box 1: Recommendations for daily practice}

Daily practice is crucial to progress in meditation, since daily practice will serve to disrupt the cognitive, affective, and neural patterns that promote inner psychological barriers to compassion while strengthening compassionate capacities. While healthcare providers do not have time for long meditation sessions each day, we suggest that even brief sessions, repeated throughout the day can yield positive outcomes. With a foundation of practice in the morning, a practitioner can return to practice for short moments many times in the day-for 30 seconds, or 1 or 2 minutes at a time. With this pattern, practitioners would engage one or more of the meditations many times in the day (e.g., 10 times, 50 times or more). Then over a period of several weeks, they will have effectively engaged the practice 1000 s of times. In that way, this regimen of practice does not have to be appraised as difficult or time consuming, but rather as repeatedly replenishing, healing, and effective for establishing a core of inner security. Such frequent repetition takes advantage of neural plasticity to strengthen capacities of care for self and others. Research confirms that as little as 40 seconds of compassionate interaction can reduce patient anxiety. ${ }^{63} \mathrm{~A}$ daily practice of mediation can make such interactions more habitual and effortless.

\section{Note Box 2: Trauma-informed practice of meditation}

Although meditation practices can give immediate access to qualities of ease, relaxation, and compassion, they may also trigger emotional disturbances. ${ }^{64,65}$ This can happen when practitioners are introduced to new ways of being that challenge familiar frameworks of self, or when practitioners encounter difficult emotional patterns from their past or from current contexts. For these reasons, we encourage healthcare providers to consider the following recommendations when practicing meditation or when recommending these practices to others:

- Flexibility in choosing meditations: Start with the practices that you experience as most immediately healing. Recognize that some practices will be more or less difficult for different people. One kind of field of care practice, for example, might be a difficult starting point for some people. Another type of field of care meditation may work better (e.g., bringing to mind a caring moment, or a benefactor, or a spiritual figure, etc.). For some people with past relationship trauma, starting with the compassionate presence to feelings practice may be more beneficial.

- Use meditations to process difficult feelings: The field of care meditation or compassionate presence to feelings meditation can serve as defaults for processing difficulties that arise in meditation, work, and life in healing ways. When you experience a difficult feeling during your day or within a meditation, you can default to either of those practices, whichever is most accessible, to process that feeling.

- Peer support and mutual self-help: Ongoing meditation practice is ideally supported by a network of practitioners that also engage in similar practices. A community of support provides a context in which practitioners can share and consult with each other as difficulties inherently arise in practice and in daily life. ${ }^{65}$

- Meditation is not sufficient on its own: Meditation should not be considered a replacement for other forms of support, such as mental health treatment or institutional support and policies. 


\section{Key Web Resources}

\begin{tabular}{|l|l|}
\hline Purpose & $\mathrm{URL}$ \\
\hline $\begin{array}{l}\text { Foundation for Active Compassion offers } \\
\text { guided meditations, recorded lectures, access } \\
\text { to regular meditation groups, and a schedule } \\
\text { of meditation retreats that support further } \\
\text { exploration of the meditations described in } \\
\text { this chapter. }\end{array}$ & https://foundationforactivecompassion.org/ \\
\hline $\begin{array}{l}\text { Courage of Care offers training in compassion } \\
\text { practices combined with anti-oppression } \\
\text { education to inform community building, } \\
\text { compassionate work environments, and social } \\
\text { activism. }\end{array}$ & http://courageofcare.org \\
\hline $\begin{array}{l}\text { Mind \& Life Institute bridges contemplative } \\
\text { traditions with science to understand the mind } \\
\text { and promote human flourishing. }\end{array}$ & https://www.mindandlife.org/ \\
\hline
\end{tabular}


Figure 1: Three compassion meditations and their purpose

\begin{tabular}{|l|}
\hline \multicolumn{1}{|c|}{ 1. Field of care } \\
Establish an outer and inner secure \\
base from which to become present \\
to self and others with unconditional \\
care.
\end{tabular}
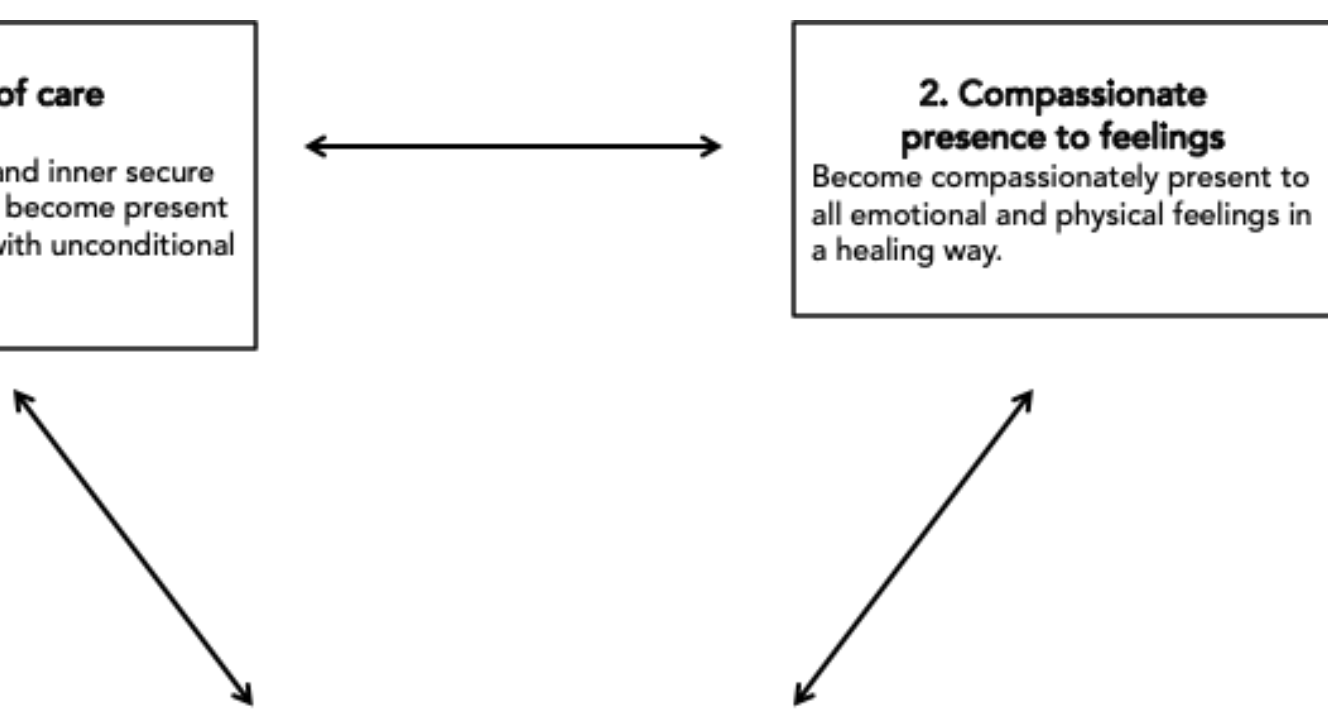

3. Taking empathy into compassion instead of empathic distress

Transform the pain of empathy into the energy and motivation of compassion for action. 


\section{References}

1. Zaki J. The caregiver's dilemma: in search of sustainable medical empathy. The Lancet. 2020;396(10249):458-459. doi:10.1016/S0140-6736(20)31685-8

2. Patel $S$, Pelletier-Bui A, Smith $S$, et al. Curricula for empathy and compassion training in medical education: A systematic review. PLOS ONE. 2019;14(8):e0221412.

doi:10.1371/journal.pone.0221412

3. Rakel D. The Compassionate Connection: The Healing Power of Empathy and Mindful Listening. W. W. Norton \& Company; 2018.

4. Decety J, Yang C-Y, Cheng Y. Physicians down-regulate their pain empathy response: An event-related brain potential study. Neurolmage. 2010;50(4):1676-1682.

doi:10.1016/j.neuroimage.2010.01.025

5. Sinclair S, Hack TF, McClement S, Raffin-Bouchal S, Chochinov HM, Hagen NA. Healthcare providers perspectives on compassion training: a grounded theory study. BMC Medical Education. 2020;20(1). doi:10.1186/s12909-020-02164-8

6. Butler EA, Egloff B, WIhelm FH, Smith NC, Erickson EA, Gross JJ. The social consequences of expressive suppression. Emotion. 2003;3(1):48-67. doi:10.1037/1528-3542.3.1.48

7. Richards JM, Butler EA, Gross JJ. Emotion Regulation in Romantic Relationships: The Cognitive Consequences of Concealing Feelings. Journal of Social and Personal Relationships. 2003;20(5):599-620. doi:10.1177/02654075030205002

8. Dean W, Talbot S, Dean A. Reframing Clinician Distress: Moral Injury Not Burnout. Fed Pract. 2019;36(9):400-402.

9. Fernando AT, Consedine NS. Beyond Compassion Fatigue: The Transactional Model of Physician Compassion. Journal of Pain and Symptom Management. 2014;48(2):289-298. doi:10.1016/j.jpainsymman.2013.09.014

10. Halpern J. What is clinical empathy? J GEN INTERN MED. 2003;18(8):670-674. doi:10.1046/j.1525-1497.2003.21017.x

11. Haque OS, Waytz A. Dehumanization in Medicine: Causes, Solutions, and Functions. Perspect Psychol Sci. 2012;7(2):176-186. doi:10.1177/1745691611429706

12. Zaki J, Cikara M. Addressing Empathic Failures: Current Directions in Psychological Science. Published online December 10, 2015. doi:10.1177/0963721415599978

13. Bride BE, Radey M, Figley CR. Measuring compassion fatigue. Clinical Social Work Journal. 2007;35(3):155-163. doi:10.1007/s10615-007-0091-7

14. Coetzee SK, Klopper HC. Compassion fatigue within nursing practice: A concept analysis. Nursing \& Health Sciences. 2010;12(2):235-243. doi:10.1111/j.1442-2018.2010.00526.x

15. Crane M. Why burned-out doctors get sued more often. Med Econ. 1998;75(10):210-212, 215-218.

16. Haas JS, Cook EF, Puopolo AL, Burstin HR, Cleary PD, Brennan TA. Is the professional satisfaction of general internists associated with patient satisfaction? J GEN INTERN MED. 2000;15(2):122-128. doi:10.1046/j.1525-1497.2000.02219.x

17. Shanafelt TD, West C, Zhao X, et al. Relationship Between Increased Personal Well-Being and Enhanced Empathy Among Internal Medicine Residents. J Gen Intern Med. 2005;20(7):559-564. doi:10.1111/j.1525-1497.2005.0108.x

18. Shanafelt TD, Hasan O, Dyrbye LN, et al. Changes in Burnout and Satisfaction With Work- 
Life Balance in Physicians and the General US Working Population Between 2011 and 2014. Mayo Clinic Proceedings. 2015;90(12):1600-1613. doi:10.1016/j.mayocp.2015.08.023

19. Ekman E, Krasner M. Empathy in medicine: Neuroscience, education and challenges. Medical Teacher. 2017;39(2):164-173. doi:10.1080/0142159X.2016.1248925

20. Mascaro JS, Kelley S, Darcher A, et al. Meditation buffers medical student compassion from the deleterious effects of depression. The Journal of Positive Psychology. 2018;13(2):133142. doi:10.1080/17439760.2016.1233348

21. Condon $P$, Makransky J. Recovering the relational starting point of compassion training: $A$ foundation for sustainable and inclusive care. Perspectives on Psychological Science. Published online 2020. doi:10.31231/osf.io/dmxj7

22. Condon $P$, Makransky J. Sustainable Compassion Training: Integrating meditation theory with psychological science. Front Psychol. 2020;11. doi:10.3389/fpsyg.2020.02249

23. Gillath O, Karantzas G. Attachment security priming: a systematic review. Current Opinion in Psychology. 2019;25:86-95. doi:10.1016/j.copsyc.2018.03.001

24. Mikulincer M, Shaver PR, Gillath O, Nitzberg RA. Attachment, Caregiving, and Altruism: Boosting Attachment Security Increases Compassion and Helping. Journal of Personality and Social Psychology. 2005;89(5):817-839. doi:10.1037/0022-3514.89.5.817

25. Mikulincer M, Shaver PR. Boosting attachment security in adulthood: The "broaden-andbuild" effects of security-enhancing mental representations and interpersonal contexts. In: Simpson JA, Rholes WS, eds. Attachment Theory and Research: New Directions and Emerging Themes. Guilford; 2015:124-144.

26. Schnall S, Roper J, Fessler DMT. Elevation Leads to Altruistic Behavior. Psychol Sci. 2010;21(3):315-320. doi:10.1177/0956797609359882

27. Barsalou LW. Grounded cognition. Annual Review of Psychology. 2008;59:617-645. doi:10.1146/annurev.psych.59.103006.093639

28. Barsalou LW. Situated conceptualization offers a theoretical account of social priming. Current Opinion in Psychology. 2016;12:6-11. doi:10.1016/j.copsyc.2016.04.009

29. Barrett LF, Gross J, Christensen TC, Benvenuto M. Knowing what you're feeling and knowing what to do about it: Mapping the relation between emotion differentiation and emotion regulation. Cognition and Emotion. 2001;15(6):713-724. doi:10.1080/02699930143000239

30. Grossmann I, Oakes H, Santos HC. Wise reasoning benefits from emodiversity, irrespective of emotional intensity. Journal of Experimental Psychology: General. 2019;148(5):805-823. doi:10.1037/xge0000543

31. Kashdan TB, Barrett LF, McKnight PE. Unpacking Emotion Differentiation: Transforming Unpleasant Experience by Perceiving Distinctions in Negativity. Curr Dir Psychol Sci. 2015;24(1):10-16. doi:10.1177/0963721414550708

32. Quoidbach J, Gruber J, Mikolajczak M, Kogan A, Kotsou I, Norton MI. Emodiversity and the emotional ecosystem. Journal of Experimental Psychology: General. 2014;143(6):20572066. doi:10.1037/a0038025

33. Wegner DM. When the Antidote is the Poison: Ironic Mental Control Processes. Psychol Sci. 1997;8(3):148-150. doi:10.1111/j.1467-9280.1997.tb00399.x

34. Wegner DM, Erber R, Zanakos S. Ironic processes in the mental control of mood and moodrelated thought. Journal of Personality and Social Psychology. 1993;65(6):1093-1104. doi:10.1037/0022-3514.65.6.1093 
35. Gross JJ, Levenson RW. Emotional suppression: Physiology, self-report, and expressive behavior. Journal of Personality and Social Psychology. 1993;64(6):970-986.

doi:10.1037/0022-3514.64.6.970

36. Mauss IB, Gross JJ. Emotion suppression and cardiovascular disease: Is hiding feelings bad for your heart? In: Emotional Expression and Health: Advances in Theory, Assessment and Clinical Applications. Brunner-Routledge; 2004:61-81.

37. Mendes WB, Reis HT, Seery MD, Blascovich J. Cardiovascular correlates of emotional expression and suppression: Do content and gender context matter? Journal of Personality and Social Psychology. 2003;84(4):771-792. doi:10.1037/0022-3514.84.4.771

38. Appleton AA, Kubzansky LD. Emotion regulation and cardiovascular disease risk. In: Handbook of Emotion Regulation, 2nd Ed. Guilford Press; 2014:596-612.

39. Uchino BN, Smith TW, Holt-Lunstad J, Campo R, Reblin M. Stress and illness. In: Handbook of Psychophysiology, 3rd Ed. Cambridge University Press; 2007:608-632. doi:10.1017/СBO9780511546396.026

40. Brackett M. Permission to Feel: Unlocking the Power of Emotions to Help Our Kids, Ourselves, and Our Society Thrive. Celadon Books; 2019.

41. Menakem R. My Grandmother's Hands: Racialized Trauma and the Pathway to Mending Our Hearts and Bodies. Central Recovery Press; 2017.

42. Thompson RA. Socialization of emotion and emotion regulation in the family. In: Handbook of Emotion Regulation, 2nd Ed. Guilford Press; 2014:173-186.

43. von Scheve C. Emotion Regulation and Emotion Work: Two Sides of the Same Coin? Front Psychol. 2012;3. doi:10.3389/fpsyg.2012.00496

44. Barrett LF. How Emotions Are Made: The Secret Life of the Brain. Houghton Mifflin; 2017.

45. Barrett LF. Emotions are real. Emotion. 2012;12(3):413-429. doi:10.1037/a0027555

46. Winnicott DW. The theory of the parent-infant relationship. Int J Psychoanal. 1960;41:585595.

47. Hoffman K. Taking refuge in the family of things. The Arrow. 2015;2:1-30.

48. Lindsay EK, Creswell JD. Mechanisms of mindfulness training: Monitor and Acceptance Theory (MAT). Clinical Psychology Review. 2017;51:48-59. doi:10.1016/j.cpr.2016.10.011

49. Lindsay EK, Chin B, Greco CM, et al. How mindfulness training promotes positive emotions: Dismantling acceptance skills training in two randomized controlled trials. Journal of Personality and Social Psychology. 2018;115(6):944-973. doi:10.1037/pspa0000134

50. Hayes SC. Buddhism and acceptance and commitment therapy. Cognitive and Behavioral Practice. 2002;9(1):58-66. doi:10.1016/S1077-7229(02)80041-4

51. Robins CJ, Schmidt III H, Linehan MM. Dialectical Behavior Therapy: Synthesizing Radical Acceptance with Skillful Means. In: Mindfulness and Acceptance: Expanding the CognitiveBehavioral Tradition. Guilford Press; 2004:30-44.

52. Cameron CD, Payne BK. Escaping affect: How motivated emotion regulation creates insensitivity to mass suffering. Journal of Personality and Social Psychology. 2011;100(1):115. doi:10.1037/a0021643

53. Cameron CD, Hutcherson CA, Ferguson AM, Scheffer JA, Hadjiandreou E, Inzlicht M. Empathy is hard work: People choose to avoid empathy because of its cognitive costs. Journal of Experimental Psychology: General. 2019;148(6):962-976.

doi:10.1037/xge0000595 
54. Zaki J. Empathy: A motivated account. Psychological Bulletin. 2014;140(6):1608-1647. doi:10.1037/a0037679

55. Schumann K, Zaki J, Dweck CS. Addressing the empathy deficit: Beliefs about the malleability of empathy predict effortful responses when empathy is challenging. Journal of Personality and Social Psychology. 2014;107(3):475-493. doi:10.1037/a0036738

56. Beckes L, Coan JA. Social Baseline Theory: The Role of Social Proximity in Emotion and Economy of Action. Social and Personality Psychology Compass. 2011;5(12):976-988. doi:10.1111/j.1751-9004.2011.00400.x

57. Coan JA, Sbarra DA. Social Baseline Theory: the social regulation of risk and effort. Current Opinion in Psychology. 2015;1:87-91. doi:10.1016/j.copsyc.2014.12.021

58. Coan JA, Schaefer HS, Davidson RJ. Lending a Hand: Social Regulation of the Neural Response to Threat. Psychol Sci. 2006;17(12):1032-1039. doi:10.1111/j.14679280.2006.01832.x

59. Blascovich J. The biopsychosocial model of challenge and threat: Reflections, theoretical ubiquity, and new directions. In: Neuroscience of Prejudice and Intergroup Relations. Psychology Press; 2013:229-242.

60. Borman GD, Rozek CS, Pyne J, Hanselman P. Reappraising academic and social adversity improves middle school students' academic achievement, behavior, and well-being. PNAS. Published online July 24, 2019:201820317. doi:10.1073/pnas.1820317116

61. Jamieson JP, Peters BJ, Greenwood EJ, Altose AJ. Reappraising Stress Arousal Improves Performance and Reduces Evaluation Anxiety in Classroom Exam Situations. Social Psychological and Personality Science. 2016;7(6):579-587. doi:10.1177/1948550616644656

62. Jamieson JP, Nock MK, Mendes WB. Mind over matter: Reappraising arousal improves cardiovascular and cognitive responses to stress. Journal of Experimental Psychology: General. 2012;141(3):417-422. doi:10.1037/a0025719

63. Fogarty LA, Curbow BA, Wingard JR, McDonnell K, Somerfield MR. Can 40 seconds of compassion reduce patient anxiety? J Clin Oncol. 1999;17(1):371-379. doi:10.1200/JCO.1999.17.1.371

64. Lindahl JR, Fisher NE, Cooper DJ, Rosen RK, Britton WB. The varieties of contemplative experience: A mixed-methods study of meditation-related challenges in Western Buddhists. PLOS ONE. 2017;12(5):e0176239. doi:10.1371/journal.pone.0176239

65. Treleaven DA. Trauma-Sensitive Mindfulness: Practices for Safe and Transformative Healing. W. W. Norton \& Co; 2018. 